\title{
Precisiones al recientemente descubierto epígrafe de Cn. Pompeyo Magno en Carthago Nova
}

\author{
Some precisions to the newly discovered inscription of \\ Pompeius the Great in Carthago Noua
}

\author{
Luis AmeLA VALVERDE* \\ RESUMEN \\ ABSTRACT \\ Recientemente se ha descubierto en la \\ ciudad de Carthago Nova un epígrafe en \\ el que parece leerse el nombre de Cn. \\ Pompeyo Magno (cos. I 70 a.C.), el \\ famoso político y militar romano. Análisis \\ de esta inscripción y nueva propuesta de \\ interpretación de su texto. \\ It has recently discovered in the city of \\ Carthago Nova a epigraph in which seems \\ to read the name of $\mathrm{Cn}$. Pompey the Great \\ (cos. I $70 \mathrm{BC}$ ), the famous Roman \\ politician and soldier. Analysis of this \\ inscription and new interpretation of its \\ text. \\ PALABRAS CLAVE \\ Pompeyo Magno, Carthago Nova, \\ epigrafía, evergetismo.

\section{KEYWORDS} \\ Pompey the Great, Carthago Nova, \\ epigraphy, evergetism.
}

Recibido el 28 de mayo de 2012. Aceptado el 5 de agosto de 2012

No queremos iniciar este artículo sin ofrecer un afectuoso recuerdo a la figura de G. Alföldy, a quien conocimos en el I Congreso Internacional de Historia Antigua celebrado en Valladolid en el año 2000, en el que exponíamos precisamente una reflexión al epígrafe de $\mathrm{Cn}$. Pompeyo Magno (cos. I 70 a.C.) hallado en la ciudad de Tarragona ${ }^{1}$.

* Grupo CEIPAC, Universitat de Barcelona. E-Mail: amelavalverde @ gmail.com Este trabajo se inserta en el Proyecto I+D+I 2011-2013 HAR2011-24593. Quiero dar las gracias a J. M. Abascal Palazón, D. Borja Ariño, J. Gómez-Pantoja, Á. A. Jordán Lorenzo, LL. Pons Pujol, F. Martín González, S. F. Ramallo Asensio y J. Remesal Rodríguez por facilitarme información y apreciaciones sobre el presente trabajo. El texto aquí presentado es responsabilidad única del autor.

1 AMELA VALVERDE, Luis, «RIT 1 y 2. La ciudad de Tarraco entre pompeyanos y cesarianos», en Actas del I Congreso Internacional de Historia Antigua. La Península Ibérica hace 2000 años (Valladolid, 2002), pp. 145-151 
Últimamente aparecen numerosas noticias de la especial vinculación entre el conocido militar y político de la República Tardía, Cn. Pompeyo Magno (cos. I 70 a.C. $)^{2}$, y la importante ciudad mediterránea de Carthago Nova (Cartagena, prov. Murcia), ubicada en la provincia de Hispania Citerior. Por un lado, la teoría de que la colonia de Carthago Nova fue creada por Pompeyo en los últimos años de la década de los años 50 a.C. (concretamente en el año 54 a.C.) ${ }^{3}$ y, por otro, el extraordinario hallazgo de un epígrafe dedicado a este personaje en esta ciudad.

Nuestra intención inicial era abordar estos dos aspectos. Pero como nosotros ya tratamos anteriormente la (im)posibilidad de que Carthago Nova fuese elevada al estatuto de colonia romana por Pompeyo ${ }^{4}$, nos centraremos en el epígrafe recientemente encontrado en esta localidad. Pero, hay que aclarar que ambos elementos han sido asociados.

2 Sobre este importante personaje de la República Tardía, vid: OOTEGHEM, J. VAN, Pompée le Grand, bâtisseur d'Empire, Bruxelles, Palais des Académies, 1954. LEACH, John, Pompey the Great, London, Croom Helm, 1978. GREENHALGH, Peter, Pompey, the roman Alexander, London, Weidenfeld and Nicolson, 1980; Pompey, the republican prince, London, Weidenfeld and Nicolson 1981. GELZER, Matthias, Pompeius: Lebensbild eines römers, Stuttgart, König Verlag, 1984. SEAGER, Robin, Pompey the Great: a political biography, Oxford, Basil Blackwell, 2002. SOUTHERN, Pat, Pompey the Great, Charleston, The History Press LTD, 2002. AMELA VALVERDE, Luis, Cneo Pompeyo Magno, el defensor de la República romana, Madrid, Signifer Libros, 2003. CHRIST, Karl, Pompeyo, Barcelona, Herder, 2006. FIELDS, Nic, Pompey. Leadership, Strategy, Conflict, Oxford, Osprey Publishing, 2012.

3 ABASCAL PALAZÓN, José Manuel, «La fecha de la promoción colonial de Carthago Nova y sus repercusiones edilicias», Mastia, 1 (2002), pp. 21-44, en concreto p. 32; «Los tres viajes de Augusto a Hispania y su relación con la promoción jurídica de ciudades», Iberia, 9 (2006), pp. 63-78, en concreto p. 67. RIPOLLÈS, Pere Pau. Y VELAZA, Javier, «Saguntum, colonia latina», ZPE, 141 (2002), pp. 285-291, en concreto p. 289. RIPOLLÈS, Pere Pau, «Las acuñaciones antiguas de la península ibérica: dependencias e innovaciones», en XIII Congreso Internacional de Numismática Madrid - 2003. Actas - Proceedings - Actes I (Madrid, Ministerio de Cultura, 2005), pp. 187-208, en concreto p. 199; «Coinage and Identity in the Roman Provinces: Spain», en Coinage and Identity in the Roman provinces (Oxford, Oxford University Press, 2005), pp. 79-93, en concreto p. 88. DÍAZ ARIÑO, Borja: Epigrafía latina republicana de Hispania (ELRH), Barcelona, 2008, p. 99; «Las murallas romanas de Cartagena en la segunda mitad del siglo I a.E.», Zephyrus, 61, (2008), pp., 225-234, en concreto p. 226-227; “Un quaestor pro praetore republicano en Carthago Noua», JRA, 21, (2008), pp. 255-263, en concreto p. 258; «Epigrafia y gobernadores provinciales en Hispania durante la República romana», Chiron, 41, (2011), pp. 149-179, en concreto p. 169. CABALLOS RUFINO, Antonio, «Colonizzazione cesariana, legislazione municipale e integrazione provinciale: la Provincia Hispania Ulterior», en Cesare: precursore o visionario? Atti del convengo internazionale (Pisa, ETS, 2010), pp. 63-84, en concreto p. 64. OLESTI VILA, Oriol, «Los veteranos de Cneo Pompeyo y Quinto Cecilio Metelo Pío en la Hispania Citerior», en Dialéctica histórica y compromiso social. Homenaje a Domingo Plácido, vol. 2 (Zaragoza, Pórtico, 2010), pp. 1007-1028, en concreto p. 1022. RAMALLO ASENSIO, Sebastián F. Y MARTÍNEZ ANDREU, Miguel, «El puerto de Carthago Nova: eje de vertebración de la actividad comercial en el sureste de la Península Ibérica», BoIlettino di Archeologia on line 1, volumen special (2010), pp. 141-159, en concreto p. 141. RAMALLO ASENSIO, Sebastián F. Y RUIZ VALDERAS, Elena, «Carthago de Hispania, emporio comercial del Mediterráneo occidental», en Simulacra Romae II. Rome, las capitales de province (capita provinciarum) et la création d'un espace commun européen. Une aproche archéologique (Reims, Societé Archéologique Champenoise, 2010), pp. 95-110, en concreto p. 103. NOVILLO LÓPEZ, Miguel Ángel, César y Pompeyo en Hispania. Territorio de ensayo jurídico-administrativo en la tardía República romana, Madrid, Sílex, pp. 114 y 273.

4 AMELA VALVERDE, Luis, «Sobre la colonia pompeyana de Carthago Nova. La cronología de RPC 149-150", en Moneta qua scripta. La moneda como soporte de escritura. Actas del III Encuentro Peninsular de Numismática Antigua (EPNA) (Madrid, CSIC-Universidad de Sevilla, 2004), pp. 367-375. 
Eso sí, antes de entrar en detalle, los argumentos para fechar desde un punto de vista cronológico la posible colonia pompeyana de Carthago Nova son de carácter numismático, basado en el alto número conocido de duunviros quinquenales que aparecen en las monedas y que, de manera hipotética, acuñarían cada cinco años, por lo que desde la última emisión con una fecha definida (en tiempos del emperador Calígula [37-41 d.C.]), y calculando el total de quinquenales, se puede llegar a mediados del s. I a.C. Como muy bien indica Ramallo, esto supondría una estricta acuñación regular en los intervalos dictados por la magistratura quinquenal y asumir que todos los quinquenales de este largo periodo emitieron moneda, algo que no está probado 5 .

Por desgracia, las monedas de Carthago Nova tienen una atribución compleja, debido a que en muchas de ellas no figura el nombre de la ciudad y su asignación se basa en la presencia de duunviros quinquenales y en los hallazgos monetarios ${ }^{6}$. Así pues, toda reconstrucción del orden y cronología de las emisiones de esta ciudad es hipotética. El análisis que de esta cuestión efectuamos mostró que no podía demostrarse que Carthago Nova fuese una colonia pompeyana, y tendríamos de nuevo que remitirnos a una fundación (post)cesariana.

Pero, esta cuestión creemos que ha influido en el análisis de un gran descubrimiento efectuado en la actual ciudad de Cartagena: el de un epígrafe en el que parece mencionarse al gran Pompeyo.

Durante el año 2005, al efectuarse la cimentación del Museo del Teatro Romano, ubicado en el Palacio de Riquelme, al pie de la ladera occidental del Cerro de la Concepción (el mons Aesculapii de Polibio [Pol. 10, 10], la elevación de mayor envergadura de las cinco que conformaban el perímetro de Carthago Nova, muy cerca de donde se supone que estuvieron en la Antigüedad las instalaciones portuarias), se encontraron los restos fragmentarios de un epígrafe, que aportaría una valiosa información según sus descubridores sobre el papel desempeñado por Pompeyo en esta ciudad o, más bien, sobre algún personaje relacionado con él que estuviera vinculado en la dotación de las infraestructuras básicas de Carthago Nova, y lo que es utilizado para vincular a Pompeyo con la transformación jurídica de esta población ${ }^{7}$, es decir, su constitución en colonia, cosa que ya hemos negado anteriormente.

El epígrafe en cuestión está grabado sobre la cara frontal del brocal triangular de un lacus rectangular, efectuado sobre tres bloques de caliza gris local, reutili-

5 RAMALLO ASENSIO, Sebastián F., "Carthago Nova: urbs opulentissima omnium in Hispania», en Early Roman Towns in Hispania Tarraconensis (Portsmouth, University of Michigan, 2006), pp. 91-104, en concreto p. 96.

6 BLÁZQUEZ CERRATO, Carmen, «Emisiones y circulación monetaria en Hispania en época transicional (72-27 a.C.)», en Del «Imperivm» de Pompeyo a la «avctoritas» de Augusto. Homenaje a Michael Grant (Madrid, CSIC, 2008), pp. 259-277, en concreto p. 265.

7 RAMALLO ASENSIO, Sebastián F. Y MURCIA MUÑOZ, Antonio J., «Aqua et lacus en Carthago Nova. Aportaciones al estudio del aprovisionamiento hídrico en época romana», ZPE, 172, (2010), pp. 249-258, en concreto p. 249. RAMALLO, Sebastián F. Y RUIZ, Elena, Op. Cit., p. 98. 
zados en una atarjea contemporánea que discurría junto a la cimentación septentrional del Palacio de Riquelme ${ }^{8}$. Uno de los bloques corresponde a una esquina en ángulo recto, y los otros dos pertenecen a tramos rectos del despiece lapidario ${ }^{9}$. Las letras son del tipo capital cuadrada, con una altura entre 5,5 y $6 \mathrm{~cm}$, con el campo epigráfico desplazado hacia la mitad superior. Los rasgos paleográficos son característicos de época tardorrepublicana, al igual que las grandes interpunciones de tendencia cuadrada, que pueden observarse en las inscripciones más antiguas de Carthago Nova ${ }^{10}$.

Ramallo y Murcia, los editores de la inscripción, proponen con los tres fragmentos conservados la siguiente lectura del texto:

\author{
[-- ca. 26/30 --] \\ [-ca. 10] MAGN(i) I[MP(eratoris)] ITERVM \\ AQVAM · ADDV[C]END(am) · LAQVSQ(ue) · FAC(iendos?) [- ca. 4 - $]^{11}$
}

Los mencionados autores señalan que sobre el fragmento central, en donde se encuentra el cognomen Magnus, se aprecian una serie de fisuras o estrías artificiales (diferentes del cincelado), que han originado la pérdida de buena parte de su superficie, efectuadas probablemente con un cincel o scalprum de hierro, con el objetivo de borrar las letras, aunque éstas se pueden leer con claridad menos la G, que se reconoce con una mayor dificultad ${ }^{12}$. Así pues, estaríamos ante una damnatio memoriae.

No es muy difícil pensar en Pompeyo, quien se hacía llamar a sí mismo Magnus y lo utilizó como cognomen en su intento de imitar al famoso monarca macedonio Alejandro III el Grande (336-323 a.C.) ${ }^{13}$. La aparición de la aclamación imperial, así como la posible reiteración de la misma o de alguna otra magistratura restringe las probabilidades. Pompeyo celebró tres triunfos $(81,71$ y 61 a.C.) y obtuvo el consulado el mismo número de veces (70, 55 y 52 a.C.), por lo que la combinación de los dos términos de forma directa (imperator iterum), o una hipotética reiteración al consulado (magistratura que podría estar en la parte perdida del epígrafe), encajarían bien con su carrera política, sobre todo si tenemos en cuenta la

8 RAMALLO, Sebastián F. Y MURCIA, Antonio J., Op. Cit., p. 249.

9 RAMALLO, Sebastián F. Y MURCIA, Antonio J., Op. Cit., pp. 249-251 ofrecen los datos técnicos, de una forma fenomenal, que no consideramos reproducir.

10 RAMALLO, Sebastián F. Y MURCIA, Antonio J., Op. Cit., p. 250.

11 RAMALLO, Sebastián F. Y MURCIA, Antonio J., Op. Cit., p. 250. RAMALLO ASENSIO, Sebastián F., Carthago Nova. Puerto mediterráneo de Hispania, Murcia, Fundación CajamMurcia, 2011, p. 76.

12 RAMALLO, Sebastián F. Y MURCIA, Antonio J., Op. Cit., p. 250. RAMALLO, Sebastián F. Y RUIZ, Elena, Op. Cit., p. 103.

${ }_{13}$ Sobre este tema, BASIRICÒ, Maria, Pompeo Magno e l'imitatio Alexandri, Roma, Gruppo Albatros II Filo, 2011. 
relación de Pompeyo con Hispania ${ }^{14}$. Precisamente la reiteración es un elemento que permite descartar a los dos hijos de Pompeyo (aunque hay que señalar que ambos fueron aclamados imperatores) ${ }^{15}$.

Por otro lado, un segundo epígrafe, un bloque de caliza gris local igual que los anteriores, de características y morfología similar al descrito anteriormente, grabado sobre el remate de otro lado, descubierto en el año 2007 en una intervención de urgencia efectuada en la Plaza Roldán, al pie de la ladera occidental del Monte Sacro, permitiría confirmar la lectura del primer texto y contribuir a su interpretación, pues conserva parte de una inscripción similar que ayuda a completar la lectura ${ }^{16}$, en la que puede leerse perfectamente la palabra IMP.

Este nuevo epígrafe presenta los mismos rasgos paleográficos que el texto anterior, aunque el tamaño de las letras es ligeramente superior, al oscilar entre los 7,4 y los $8 \mathrm{~cm}$ de altura. Pueden apreciarse en el extremo derecho de la pieza dos improntas para alojar grapas de plomo en forma de milano, dispuestas respectivamente en cada una de sus caras abatidas. En la superficie pueden observarse señales acentuadas de erosión, que no sólo atestiguan un uso prolongado sino que podrían así mismo ser indicio de la profundidad del depósito receptor de las aguas ${ }^{17}$.

14 Sobre este tema, vid: AMELA VALVERDE, Luis, «El desarrollo de la clientela pompeyana en Hispania», SHHA 7 (1989), pp. 105-117; «La amonedación pompeyana en Hispania. Su utilización como medio propagandístico y como reflejo de la clientela de la gens Pompeia», Faventia, 12-13, (1990-1991), pp. 181-197; «Las ciudades fundadas por Pompeyo Magno en Occidente: Pompaelo, Lugdunum Convenarum y Gerunda», Polis, 12 (2000), pp. 7-41; «La turma Salluitana y su relación con la clientela pompeyana», Veleia, 17, (2000), pp. 79-92; «Las concesiones de ciudadanía romana: Pompeyo Magno e Hispania», MHA, 21-22, (2000-20001), pp. 91-103; «El nomen Pompeius en Hispania: Algunos aspectos críticos», Emerita, 69, (2001), pp. 241-262; «Pompeyo Magno y el gobierno de Hispania en los años 55-50 a.C.», HAnt, 25, (2001), pp. 93-122; «El asesinato de Cn. Calpurnio Pisón», Gerión, 20/1, (2002), pp. 255-279; «Las emisiones de bronce con cabeza / proa de Arse-Saguntum: Una nota», GN, 147, (2002), pp. 3-14; «El nomen Pompeius en la numismática hispánica», Fortunatae, 13, (2002), pp. 9-30; “Caesar, De Bello Civile 3, 88, 3», Myrtia, 18, (2003), pp. 163-168; Las clientelas de Cneo Pompeyo Magno en Hispania, Barcelona, Universidad de Barcelona, 2003; «La conspiración contra Casio Longino», RHM, 93, (2003), pp. 11-60; «Pompeyo Magno y la guerra sertoriana: la constitución de una clientela», BMZ, 17, (2003), pp. 105-131; «Caes. BCiv. 2, 18, 7. Una nota sobre la obra de Eilers Roman Patrons of Greek Cities», Veleia, 21, (2004), pp. 303-309; «Las concesiones de ciudadanía romana: Pompeyo Magno e Hispania», AC, 73, (2004), pp. 47-107; «Emisiones militares pompeyanas del año 49 a.C. en Hispania», ETF(Hist), 15, (2004), pp. 167-180; «La campaña de Pompeyo Magno contra los piratas en Hispania (67 a.C.)», HAnt, 30, (2006), pp. 7-20; «Navarra, Roma e Hispania: Pompeyo», en Navarra en la Antigüedad: Propuesta de Actualización (Pamplona, Gobierno de Navarra, 2006), pp. 137166; «De nuevo sobre las emisiones pompeyanas RRC 446 y 447. Nueva atribución a la costa ilírica», en XIV Congreso Nacional de Numismática. Ars Metallica: Monedas y medallas (Madrid, Museo de la Casa de la Moneda, 2011), pp. 615-628; «De nuevo sobre la vía Tarraco-Oiasso», Pyrenae, 42/1, (2011), pp. 119-128..

15 RAMALLO, Sebastián F. Y RUIZ, Elena, Op. Cit., p. 103.

16 RAMALLO, Sebastián F. Y MURCIA, Antonio J., Op. Cit., p. 251. RAMALLO, Sebastián F. Y RUIZ, Elena, Op. Cit., p. 99.

17 RAMALLO, Sebastián F. Y MURCIA, Antonio J., Op. Cit., p. 251. 
Las dos inscripciones conmemorarían la conducción de agua a la ciudad a través de un acueducto (aquam) y la construcción de, como mínimo, dos fuentes públicas (lacus) asociadas a la instalación, como atestigua el propio texto: aquam adducendum laquosq(ue) fac[iendos $]^{18}$.

En cuanto a la primera inscripción, Ramallo y Murcia señalan que puede restituirse tanto coer(avit), un arcaísmo documentado en Carthago Nova en otros epígrafes de época tardo-republicana (CCDNE $1=\mathrm{CIL} \mathrm{I}^{2} 2271=\mathrm{CIL} \mathrm{II} 3434=\mathrm{CIL}$ II 5927 = ELRH C10. CCDNE $34=$ CIL I $2269=$ CIL II $3408=$ ELRH C15. CCDNE $222=\mathrm{CIL} \mathrm{I}^{2} 3349=$ ELRH C49) ${ }^{19}$ como cur(avit), aunque los editores se inclinan más por la primera solución, por más que señalan que hay que tener en cuenta que en las inscripciones de este periodo es muy frecuente el desarrollo completo de ambas formas verbales, sobre todo de la primera $\left(\mathrm{CIL} \mathrm{I} \mathrm{I}^{2} 1722=\mathrm{CIL}\right.$ IX $1140=$ ILLRP 523 = ILS 5318. CIL I² 1522-1523 = CIL X $5837=$ ILLRP $584=$ ILS 5342. CIL I2 1524 = CIL X $5840=$ ILLRP $585=$ ILS 5343. CIL I $^{2} 1525=$ CIL X $5839=$ ILLRP 586 = ILS 5344. CIL I² 1559 = CIL X $6239=$ ILLRP $603=$ ILS 5324. CIL I ${ }^{2}$ 1554 = CIL X 6327 = ILLRP 673). Así mismo, sería imposible restituir la fórmula f(aciendum) $c$ (uravit) $i($ dem)q(ue) p(robavit), que aparece en algunos epígrafes de la serie de textos que aluden a la construcción del recinto amurallado ya en tiempos de Augusto CCDNE $3=$ CIL II 3425. CCDNE $4=$ EE IX 331. CCDNE $5=$ CIL II 3426 = ELRH C28), puesto que en la presente inscripción el desarrollo del primer vocablo es incuestionable ${ }^{20}$.

Según Ramallo y Murcia, la inscripción se distribuiría de una manera regular al menos por tres lados del brocal del lacus, lo que obligaría según ellos a considerar la existencia de un segundo personaje en nominativo al comienzo del texto (así pues, en la línea perdida), relacionado con el principal, Pompeyo, ubicado en la cara frontal del epígrafe, el cual habría sido realmente quien habría promovido la obra (a quien por desgracia no conoceríamos); de esta forma presuponen en la restitución que en la cara izquierda figuraría el nombre completo del promotor de la obra, en el frontal aparecería el nombre del personaje más importante (esto es, Pompeyo), mientras que en lado restante, la cara derecha, figuraría la actividad desarrollada ${ }^{21}$, vid infra.

Pero, no adelantemos acontecimientos. En primer lugar, sobre la identidad del individuo que figura en el presente epígrafe (siempre que se considere que se trata del mismo y no sea diferente), del que únicamente conocemos su cognomen, Magnus, y que fue imperator, no parece que haya mucha duda de que se trate del conocido triunviro Cn. Pompeyo Magno (cos. I 70 a.C.), al que hemos dedicado va-

18 RAMALLO, Sebastián F. Y MURCIA, Antonio J., Op. Cit., pp. 251-252. RAMALLO, Sebastián F. Y RUIZ, Elena, Op. Cit., p. 99. RAMALLO, Sebastián F., Carthago Nova. Puerto mediterráneo..., Op. Cit., p. 76.

19 RAMALLO, Sebastián F. Y MURCIA, Antonio J., Op. Cit., p. 250 n. 5 señalan que la forma abreviada fac(iendum) coer(avunt) se da en dos inscripciones, una en Fondi (CIL I ${ }^{2} 1557 \mathrm{a}=\mathrm{CIL}$ X $6238=$ ILLRP 601 =ILS 6280) y otra en Emporiae (CIL I² 2673 = ILLRP 581).

20 RAMALLO, Sebastián F. Y MURCIA, Antonio J., Op. Cit., pp. 250-251.

21 RAMALLO, Sebastián F. Y MURCIA, Antonio J., Op. Cit., p. 251. 
rios estudios acerca de los epígrafes conmemorativos en su honor ${ }^{22}$. Ramallo y Murcia consideran, siguiendo el cursus honorum de este personaje, que Pompeyo tendría una relación directa con la ciudad: durante la etapa de Pompeyo como gobernador de la Hispania Citerior durante la guerra sertoriana (77-71 a.C.) y, posteriormente, en este mismo cargo, antes de la guerra civil entre el Senado y C. Julio César (cos. I 59 a.C.) (55-49 a.C.), aunque en este último periodo Pompeyo ejerció el gobierno de la Península a través de legados, si bien no hay que descartar que en algún momento éste pudiera venir a Hispania.

En este marco, Carthago Nova aparece relacionada con el posterior triunviro. Así, en el año 76 a.C., la población sufrió el sitio de las fuerzas sertorianas, cuya defensa corrió a cargo de C. Memio, cuñado de Pompeyo, lo que le impidió unirse a este último (Cic. Balb. 5) ${ }^{23}$. Igualmente, para Ramallo y Murcia, quizás Carthago Nova fue una de las ciudades marítimas que el propio Pompeyo menciona en una carta dirigida al Senado durante este conflicto (Sall. Hist. 2, 98, 9) ${ }^{24}$. Como indican los citados autores, no hay que descartar la presencia del propio Pompeyo en la ciudad ${ }^{25}$.

Tras la finalización de la guerra sertoriana, Pompeyo partió hacia Italia y no se tienen noticias que pongan en relación a este personaje con esta ciudad. En cualquier caso, nosotros mismos hemos señalado que el puerto de Carthago Nova pudo ser una de las bases del dispositivo establecido por Pompeyo para su campaña contra los piratas que asolaban las costas hispanas ${ }^{26}$, y si bien no hay ninguna confirmación escrita, se trata de una hipótesis bastante plausible ${ }^{27}$.

22 Vid: AMELA VALVERDE, Luis, «Inscripciones honoríficas dedicadas a Pompeyo Magno», Faventia, 23/1, (2001), pp. 87-102; «RIT 1 y 2. La ciudad de Tarraco entre pompeyanos y cesarianos», en Actas del I Congreso Internacional de Historia Antigua. La Península Ibérica hace 2000 años (Valladolid, Universidad de Valladolid, 2002), pp. 145-151; «Dedicatoria a Pompeyo procedente de Side (AE 1966 462 = IK 4354 = I.Side 101)», SEBarc, 5, (2004), pp. 11-24; «Pompeyo y los honores cultuales. Algunos casos", en Actas del XXVII Congreso Internacional Girea-Arys IX. Historia Antigua. Jerarquías religiosas y control social en el mundo antiguo (Valladolid, Universidad de Valladolid, 2004), pp. 407-415; «Pompeio Magno, Italicei qvi Agrigentini negotiantvr», Gerión, 24/1, (2006), pp. 195-206; «La «nueva» inscripción de Pompeyo Magno en Claros», en XII Congressvs Internationalis Epigraphiae Graecae et Latinae. Provinciae imperii romani inscriptionibus descriptiae, Acta I (Barcelona, Universidad de Barcelona, 2007), pp. 41-48; «Una inscripción de Ilium dedicada a Pompeyo. Una nota», Arys, 7, (2006-2008), pp. 115-128; «Mileto, Esquines y Pompeyo Magno», Helmántica, 181, (2008), pp. 7-14; «El epígrafe en honor de Cn. Pompeyo Magno en Argos (AE 192081 = SEG L 361)», CFC(G), 22, (2012), pp. 169-183.

23 RAMALLO, Sebastián F. Y MURCIA, Antonio J., Op. Cit., p. 252 recuerdan así mismo que en Carthago Nova fue donde Q. Sertorio (pr. 83 a.C.) embarcó con tres mil hombres (Plut. Sert. 7, 4). El vaivén de la ciudad entre ambas fuerzas durante el presente conflicto es explicado por estos autores debido a que la fuerte presencia de comerciantes y negotiatores itálicos relacionados directamente con la explotación del territorio, pudo favorecer una cierta situación de indefinición al principio de la guerra, que se vería acentuada por el respeto y simpatía hacia el propio Sertorio.

24 RAMALLO, Sebastián F. Y MURCIA, Antonio J., Op. Cit., p. 252 n. 18.

25 RAMALLO, Sebastián F. Y MURCIA, Antonio J., Op. Cit., p. 252. Más discutible es que Carthago Nova fuese la «capital» o principal centro administrativo de la Hispania Citerior, como defienden estos investigadores, creyendo nosotros que lo sería la población de Tarraco. Sobre este tema, vid: RUIZ DE ARBULO, Joaquín, «Tarraco, Carthago Nova y el problema de la Capitalidad de la Hispania Citerior republicana», en Miscel.lània Arqueològica a Josep M. Recasens (Tarragona, 1992), 115-130. GIMENO, Jesús, «Plinio, Nat. Hist. III, 3, 21: reflexiones acerca de la capitalidad de Hispania Citerior», Latomus, 53, (1994), pp. 39-79.

${ }^{26}$ AMELA, Luis, «La campaña de Pompeyo Magno contra los piratas...», p. 19.

27 RAMALLO, Sebastián F. Y MURCIA, Antonio J., Op. Cit., pp. 252-253. 
Ciertamente, como indican Ramallo y Murcia, el descubrimiento del epígrafe de Pompeyo en Carthago Nova trae a la memoria la inscripción (fragmentaria) del mismo personaje descubierta en la otra gran ciudad de la Hispania Citerior, Tarraco $\left(\mathrm{CIL} \mathrm{I}^{2}\right.$ 2964a = ELRH C59 = HAE 487 = RIT 1), que nosotros mismos hemos estudiado, que fue inscrita en el año 71 a.C., y fue posteriormente amortizada y regrabada en la cara opuesta (CIL I2 2964b = ELRH C59 = HAE 488 = RIT 2); Pompeyo aparece como imperator iterum, aunque la segunda palabra es incierta y se ha reconstruido a partir de un epígrafe procedente de la ciudad etrusca de Clusium $(\mathrm{CIL} \mathrm{I} 2768$ = CIL XI 2104 = ILLRP 381 = ILS 876). Indudablemente, esta segunda aclamación imperatorial está relacionada con el triunfo de Pompeyo sobre Hispania ${ }^{28}$ (que no sobre Sertorio, puesto que el mos maiorum no permitía celebrar una victoria sobre un ciudadano romano), celebrado el último día del año 71 a.C.

Como indican Ramallo y Murcia, el dato es muy interesante puesto que, en correspondencia con la inscripción encontrada en Carthago Nova, ésta se fecharía tras el conflicto sertoriano y, además, descartaría que el personaje mencionado en ella fuese Cn. Pompeyo hijo, el hijo mayor de Pompeyo (con una importante presencia en Hispania pues lideró la resistencia contra César durante la guerra civil), del que conocemos que sólo gozó de esta distinción una sola vez (salvo sorpresa). También los mismos autores descartan al hijo menor de Pompeyo, Sexto, aunque, como ellos mismos indican, una emisión de monedas de oro y plata de Sicilia de este personaje (RRC 511/1-4) presenta la misma titulatura ${ }^{29}$. Quizás haya que descartar a Sexto Pompeyo más bien porque que durante su estancia en Hispania, por lo menos, en lo que se conoce en relación con la guerra contra César, único momento en que conocemos su presencia en la Península ${ }^{30}$, no creemos que estuviera por la labor de canalizar las aguas de una ciudad, aunque fuese de la importancia de Carthago Nova, si bien hay que tener presente el dato de que Sexto Pompeyo asedió esta ciudad (Dio Cass. 45, 10, 1), y la convirtió en su cuartel general (Cic. Att. 16, 4, 2).

Por tanto, habría que acepar la cronología propuesta por Ramallo y Murcia de datar esta inscripción entre la segunda (71 a.C.) y la tercera (61 a.C.) aclamación imperatorial de Pompeyo ${ }^{31}$. Ya no estamos tan de acuerdo con los citados autores en considerar que la ausencia de la mención de la magistratura del consulado en los epígrafes localizados en la ciudad de Carthago Nova, que Pompeyo desempeñó por primera vez en el año 70 a.C., podría suponer una datación de la presente inscripción anterior a esta fecha y, al mismo tiempo, posterior a la celebra-

${ }^{28}$ AMELA, Luis, «Inscripciones honoríficas...», pp. 86-88. RAMALLO, Sebastián F. Y MURCIA, Antonio J., Op. Cit., p. 253.

29 RAMALLO, Sebastián F. Y MURCIA, Antonio J., Op. Cit., p. 253.

30 Sobre la presencia de este personaje en Hispania, vid: GABBA, Emilio, «Aspetti della lotta in Spagna di Sesto Pompeo», en Legio VII Gemina (León, Cátedra de San Isidro, 1970), pp. 131-155. AMELA VALVERDE, Luis, «Sexto Pompeyo en Hispania», Fil, 12, (2001), pp. 11-46. LOWE, Benedict J., «Sextus Pompeius and Spain: 46-44 BC», en Sextus Pompeius (London, The Classical Press of WalesDuckwort 2002), pp. 65-102.

31 RAMALLO, Sebastián F. Y MURCIA, Antonio J., Op. Cit., p. 253. 
ción del triumphus, lo que supondría que sería en el año 71 a.C. cuando se llevaron a cabo los trabajos citados en el epígrafe ${ }^{32}$.

Hay que tener en cuenta que Pompeyo celebró su segundo triunfo ex Hispania el 21 de diciembre del año 71 a.C., y entraría en funciones como cónsul el 1 de enero del año 70 a.C. Es evidente que no existe tiempo material para haber ejecutado las obras de canalización de aguas; pero, como en el caso de los Trofeos de Pompeyo, ubicado en los Pirineos en la frontera entre Hispania y la Galia ${ }^{33}$, una cosa es dar la orden de construcción y otra el tiempo en que se tarda en efectuar la tarea. Claro que, en la porción conservada del epígrafe, no hay ningún elemento que pueda indicar la mención de consulado a Pompeyo, como así mismo figura en inscripciones dedicadas a este personaje en Clusium (CIL I2 $768=\mathrm{CIL}$ XI $2104=$ ILLRP 381= ILS 876) o en Roma por los negotiatores de Agrigentum (AE 193711 $=$ CIL I $2710=$ ILLRP 380).

Sin entrar en más detalles, Ramallo y Murcia consideran que Pompeyo había concedido muchos beneficios a la Hispania Citerior, donde había establecido sólidas clientelas (Caes. BCiv. 1, 29, 3) ${ }^{34}$, por lo que en este contexto podrían ubicarse los trabajos descritos en la inscripción encontrada en Carthago Nova. Estos autores señalan que una datación tan temprana para una infraestructura básica de esta ciudad, que podrían relacionarse además con otras obras públicas de interés, como las pilae et fundamenta ex caemento de un epígrafe localizado en la Torre del Homenaje del Castillo de la Concepción (CCNDE $1=\mathrm{CIL} \mathrm{I}^{2} 2271=\mathrm{CIL}$ II 3434 = ELRH C10) que, por paralelos epigráficos similares procedentes de Capua y Minturnae, pertenecerían a estos mismos años. Sin duda, como indican una vez más Ramallo y Murcia, la intensificación de la explotación de las minas de plata de los alrededores de Carthago Nova desde finales del s. II a.C., y los beneficios así obtenidos por las familias relacionadas con esta actividad se deberían reflejar sin duda en intervenciones de carácter edilicio; de esta forma, se pone como ejemplo la construcción de un sacellum por M. Aquinius Andro, liberto de una conocida gens itálica que figura en las cartelas de los lingotes de plomo $\left(\right.$ CCNDE 204) ${ }^{35}$.

Pero, a pesar de lo anterior, Ramallo y Murcia prefieren adscribir el presente epígrafe al periodo del segundo mandato de Pompeyo en la Hispania Citerior (54-49 a.C.), en el que no se conocen nexos entre este personaje y Carthago Nova, aunque sin duda la importancia excepcional de esta población estaría en

32 RAMALLO, Sebastián F. Y MURCIA, Antonio J., Op. Cit., p. 253.

33 Sobre este interesante monumento, vid: AMELA VALVERDE, Luis, «Los Trofeos de Pompeyo», Habis, 32, (2001), pp. 185-202; «Los Trofeos de Pompeyo», RdA, 364, (2011), pp. 50-57.

${ }^{34}$ Sobre éstas, vid: AMELA VALVERDE, Luis, «El desarrollo de la clientela pompeyana en Hispania», SHHA, 7, (1989), pp. 105-117; «La turma Salluitana y su relación con la clientela pompeyana», Veleia, 17, (2000), pp. 79-92; Las clientelas de Cneo Pompeyo Magno en Hispania, Barcelona, Universidad de Barcelona, 2003; «Pompeyo Magno y la guerra sertoriana: la constitución de una clientela», BMZ, 17, (2003), pp. 105-131.

35 RAMALLO, Sebastián F. Y MURCIA, Antonio J., Op. Cit., p. 253. 
mente de los legados que gobernaban la provincia de Pompeyo in absentia ${ }^{36}$. Esto, evidentemente, se relacionaría con la teoría de la conversión de la ciudad en colonia por Pompeyo, que antes hemos mencionado.

Ramallo y Murcia señalan que si bien pudiera argumentarse contra esta cronología «baja», existiría un posible desfase en el cursus de Pompeyo, puesto que éste ya habría celebrado su tercer triumphus (61 a.C.). Para solventar este problema, los citados autores contemplan una restitución alternativa al texto, incorporando la magistratura consular, con lo que se tendría la lectura: Cn(aei) Pompei Mag(ni) imp(eratoris) co(n)s(ulis) iterum, con un total de 24 letras, que se ajustarían a la estructura de la inscripción. Como justificación, Ramallo y Murcia aluden al epígrafe piceno de Auxinum en honor a Pompeyo, como patrono, en el que se menciona su condición de imperator, que adquiría un valor genérico, así como cónsul por tercera vez (CIL I 769 = CIL IX 5837 = ILLRP 382 = ILS 877), lo que llevaría a la fecha del año 52 a.C., cuando se cumple esta última condición, y se omite el número de triunfos obtenido por Pompeyo ${ }^{37}$.

De esta forma, Ramallo y Murcia efectúan la siguiente restitución del epígrafe a partir de los dos fragmentos localizados, siempre que se suponga que se trate del mismo texto:

$$
\text { [— ca. 26-30—] }
$$

Gn(aei) Pompei Magn(i) Imp(eratoris) co(n)s(ulis) iterum

Aquam adducend(am) laqusq(ue) fac(iendos?) coer(avit) ${ }^{38}$

Para estos dos autores, el que no conozcamos intervenciones evergéticas directas de Pompeyo fuera de Roma les hace descartar cualquier participación directa de éste, lo que corroboraría, según su opinión, la forma abreviada del cognomen (cfr. CIL VI 33453 = ILLRP 428). En este sentido, los escasos epígrafes conocidos de Pompeyo en Occidente son dedicaciones de carácter honorífico, aunque la citada inscripción de Auxinum ha sido interpretada como la respuesta de los ciudadanos de esta población a la concesión por parte de Pompeyo de algún tipo de favor o beneficio a esta ciudad, y aunque se desconoce su naturaleza ${ }^{39}$, podría deberse a alguna actuación de carácter evergético ${ }^{40}$.

Así pues, los editores del epígrafe consideran que Pompeyo no participó directamente en las obras hidráulicas reseñadas, por lo que consideran que al inicio de la inscripción debía figurar un personaje relacionado con el magistrado romano, quizás un cliente o subalterno suyo, tal vez un accensus, quizás un homónimo, que fuese el impulsor de la actividad evergética en cuestión ${ }^{41}$, y dan un repaso a los

\footnotetext{
36 RAMALLO, Sebastián F. Y MURCIA, Antonio J., Op. Cit., p. 253.

37 RAMALLO, Sebastián F. Y MURCIA, Antonio J., Op. Cit., p. 254.

38 RAMALLO, Sebastián F. Y MURCIA, Antonio J., Op. Cit., p. 254.

9 AMELA, Luis, «Inscripciones honoríficas...», p., 99.

40 RAMALLO, Sebastián F. Y MURCIA, Antonio J., Op. Cit., p. 254.

41 RAMALLO, Sebastián F. Y MURCIA, Antonio J., Op. Cit., p. 254.
} 
Pompeii conocidos en Carthago $\mathrm{Nova}^{42}$, un tema que nosotros queremos analizar en otra ocasión.

Así mismo, como alternativa a lo anterior, Ramallo y Murcia consideran la posible existencia de un legatus pro praetore como artífice de nuestro epígrafe, aunque no existen evidencias precisas sobre cuál era su titulación, teniendo en cuenta, como hemos dicho, que Pompeyo gobernó toda Hispania en la segunda mitad de la década de los años 50 a.C. mediante legati (App. BCiv. 2, 18. Dio Cass. 39, 39, 4. Liv. Per. 110, 1. Plut. Caes. 36, 1; Pomp. 53, 1-2. Vell. Pat. 2, 48, 1) ${ }^{43}$. Evidentemente, esto trae a la memoria el epígrafe cartagenero de [-] Herius C. $f$. Hispa[--], leg(atus) pro pr(aetore) (CCNDE 47), quien se ha relacionado con C. Herius, de la tribu Clustumina, citado en el bronce de Ascoli $\left(\mathrm{CIL} \mathrm{I}{ }^{2} 709=\mathrm{CIL}\right.$ VI $37045=$ ILLRP 515 = ILS 8888), habiéndose fechado el pedestal entre los años 67 y 49 a.C., aunque con la información disponible los editores no pueden establecer ninguna relación con Pompeyo ${ }^{44}$.

Como ejemplo, se menciona que fuera de Hispania dos partidarios de Pompeyo en la guerra civil del Senado contra C. Julio César (cos. I 59 a.C.), P. Attius Vaarus y $C$. Considius Longus, legati pro pretore impulsaron en Curubis la construcción de murum, turres, posteicus, fossam (CIL VIII $24099=$ ILLRP 394 = ILS 5319). Unos años más tarde, en Lilybaeum, L. Plinius Rufus, leg(atus) pro pr(aetore) y pr(aetor) des(ignatus), partidario de Sexto Pompeyo, se encargó de la elevación de por[ta]m et turres (ILLRP 426) ${ }^{45}$.

En este sentido, hay que recordar al magistrado que fue q(uaestor) pro pr[aetore], quien construyó los arcos y filtros, probablemente pertenecientes a un acueducto, recordados en la inscripción de un dintel de grandes proporciones con paleografía similar (AE 2008727 = CCDNE $29=$ CIL II $3421=$ ELRH C12 = EE IX 346) ${ }^{46}$. Si bien en un principio se había fechado este epígrafe en las últimas décadas del s. I a.C. ${ }^{47}$, Ramallo y Murcia habían pensado en un primer momento relacionarlo con el controvertido Q. Casio Longino (tr. pl. 49 a.C.), pero su militancia filocesariana y su vinculación a la Hispania Ulterior les ha hecho descartarlo ${ }^{48}$.

42 RAMALLO, Sebastián F. Y MURCIA, Antonio J., Op. Cit., pp. 254-255.

${ }^{43}$ RAMALLO, Sebastián F. Y MURCIA, Antonio J., Op. Cit., p. 255 n. 35 recuerdan una inscripción de Cirene de Cn. Cornelius Lentulus Marcellinus (cos. 56 a.C.) que fue legatus pro pr(aetore) Cn(aei) Pompei Magni / [im]peratoris, durante la guerra contra los piratas. (SIG ${ }^{3} 750$ ).

44 ABASCAL PALAZÓN, José Manuel Y RAMALLO ASENSIO, Sebastián F., La ciudad de Carthago Nova: la documentación epigráfica, Murcia, Universidad de Murcia, 1997, p. 188. DÍAZ ARIÑO, Borja, Epigrafía latina republicana de Hispania..., Op. Cit., p. 102. RAMALLO, Sebastián F. Y MURCIA, Antonio J., Op. Cit., p. 255. RAMALLO, Sebastián F. Y RUIZ, Elena, Op. Cit., p. 103. RAMALLO, Sebastián F., Carthago Nova. Puerto mediterráneo..., Op. Cit., p. 76.

45 RAMALLO, Sebastián F. Y MURCIA, Antonio J., Op. Cit., p. 255.

46 RAMALLO, Sebastián F. Y MURCIA, Antonio J., Op. Cit., p. 255.

47 ABASCAL, José Manuel Y RAMALLO, Sebastián F., Op. Cit., p. 144.

48 RAMALLO, Sebastián F. Y MURCIA, Antonio J., Op. Cit., p. 255 n. 39. 
Sin embargo, otros estudiosos han apostado por esta solución (para reforzar la supuesta promoción jurídica de Carthago Nova por Pompeyo) ${ }^{49}$, aunque lo fragmentado del magistrado en cuestión ha originado que incluso se piense en un personaje de inicios de época imperial, Sex. Curvius Silvinus, quaestor pro praetore, conocido gracias a un pacto de hospitalidad procedente de Munigua (CILA 5 $1053)^{50}$. J. Gómez-Pantoja (en HEP 17 90) ha criticado fuertemente, pero con razón, ambas propuestas; el comentarista de AE 2008727 también va en la misma línea.

Según los editores de nuestra inscripción, todas estas intervenciones serían complementarios a otros trabajos anteriores y precederían a la construcción de la muralla de la colonia de Carthago Nova, realizada en tramos e impulsada por la propia ciudad, que fue ejecutada a través de los magistrados: duunviros y/o ediles. Como en ninguno de estos textos epigráficos alusivos a esta construcción se hace mención expresa a un patrocinio privado, ni tan siquiera mixto, habría que considerarse que se llevó a cabo mediante la financiación pública pues, de lo contrario, en estas inscripciones habría aparecido la conocida fórmula ex $s(u a)$ $p$ (ecunia), que figura en el epígrafe citado en el párrafo anterior ${ }^{51}$. Por tanto, estaríamos de nuevo ante una prueba de la (supuesta) transformación jurídica de la ciudad por Pompeyo ${ }^{52}$, a la que hemos aludido anteriormente al inicio de este trabajo; no en vano, la construcción de murallas y el aprovisionamiento hídrico constituirían las primeras preocupaciones tras la promoción jurídica de Carthago Nova ${ }^{53}$.

Finalmente, los editores, en relación al contexto de transformación urbana precoz de la ciudad de Carthago Nova anterior a Augusto, sitúan la inscripción de M(arcus) Cal[purnius] Bibulu[s] (CCNDE 2 = CIL II $3422=$ ELRH C25), quien, si bien pudiera tratarse de un cliente homónimo del conocido cónsul del año 59 a.C., colega de César, Ramallo y Murcia consideran que pudiera tratarse del propio noble romano, el cual sería nombrado en el año 49 a.C. comandante-jefe de la flota de Pompeyo en el mar Adriático (App. BCiv. 2, 49. Caes. BCiv. 3, 5, 4. Cic. Att. 9, 9, 2. Dio Cass. 41, 44, 3. Plut. Cato Min. 54, 2-4), con base en Corcyra, donde fue designado patrono (CIG II 1880 = IG IX/1 722) y desde dónde pudo visitar la localidad cartagenera, participando en su precoz proceso de monumentalización ${ }^{54}$.

49 DÍAZ ARIÑO, Borja: Epigrafía latina republicana de Hispania..., Op. Cit., p. 104; «Las murallas romanas de Cartagena...», Op. Cit., p. 229; «Un quaestor pro praetore republicano....», Op. Cit., p. 258; «Epigrafia y gobernadores provinciales en Hispania...», Op. Cit., p. 170.

${ }_{50} \mathrm{KOCH}$, Michael, «Warum nicht Curvius Silvinus? Eine Hypothese?», MDAI(M), 51 (2010), p. 360367, en concreto p. 366.

51 RAMALLO, Sebastián F. Y MURCIA, Antonio J., Op. Cit., p. 255.

52 RAMALLO, Sebastián F. Y MURCIA, Antonio J., Op. Cit., p. 256.

53 RAMALLO, Sebastián F. Y RUIZ, E., Op. Cit., pp. 99 y 104.

${ }^{54} \mathrm{KOCH}$, Michael, «Die römische Gesellschaft von Carthago Nova nach den epigraphischen Quellen», en Festschrift für Jürgen Untermann zum 65. Geburstag (Innsbruck, 1993), pp. 191-242, en concreto p. 210. RAMALLO ASENSIO, Sebastián F., «Carthago Nova. Arqueología y epigrafía de la muralla romana», en Defensa y territorio en Hispania de los Escipiones a Augusto (León, Universidad de LeónCasa de Velázquez, 2003), pp. 325-362, en concreto p. 348. RAMALLO, Sebastián F. Y MURCIA, Antonio J., Op. Cit., p. 256. RAMALLO, Sebastián F. Y RUIZ, Elena, Op. Cit., p. 103. 
Pero, hay que advertir, en cualquier caso, que el dato del patronazgo de Calpurnio Bíbulo es erróneo, debido a que en realidad hay que leer M. Cali(dius) By$b{ }^{\circ} s^{55}$. El hecho de la similitud en la grafía de las letras y las interpunciones de este epígrafe con las dos inscripciones referentes a Pompeyo son muy estrechas según los editores, a pesar del aspecto más cuidado y monumental del epígrafe referenciado en este párrafo ${ }^{56}$.

De hecho, hay que entender que, de ser esto así, significaría en principio que el programa de construcción de las murallas de Carthago Nova se extendería durante al menos 40 años, lo que parece improbable, máximo si tenemos en cuenta que los epígrafes cartageneros sobre esta materia muestran que se trata de un conjunto uniforme y contemporáneo ${ }^{57}$. Por ello, más que el personaje consular (al que precisamente no vemos atravesando un Mediterráneo hostil), más bien puede tratarse de un itálico como un cliente de los Calpurnii Bibulp ${ }^{8}$, más difícilmente pudiera tratarse de un descendiente del cónsul adversario de César ${ }^{59}$, o éste mismo antes de asumir el gobierno de la provincia de Siria en el año 51 a.C. ${ }^{60}$ Sea como fuere, el tema está abierto y prueba la dificultad del análisis del registro epigráfico sin tener un apoyo en las fuentes literarias. Hasta aquí hemos expuesto el desarrollo efectuado por los editores de la pieza, al que hemos señalado algunos matices.

Por nuestra parte, no podemos estar más en desacuerdo con la reconstrucción del epígrafe planteada por Ramallo y Murcia. Las razones son varias. En primer lugar, y creemos más importante, es que la promoción jurídica de la ciudad de Carthago Nova por Pompeyo no es más que, permítaseme la expresión, una «ficción». Si bien esta tesis cada vez tiene mayor respaldo entre los estudiosos, el análisis que hicimos de las pruebas numismáticas que apoyarían esta solución han mostrado que esto no es correcto, y así lo señalan algunos investigadores ${ }^{61}$, pues ello implicaría cambiar la seriación de las series de monedas de la ciudad, que si bien no está bien establecida, no parece oportuna ${ }^{62}$. No entraremos en los problemas jurídicos que tal concesión supondría. De este modo, se trataría de una colonia (post)cesariana ${ }^{63}$.

55 EILERS, Claude, Roman Patrons of Greek Cities, Oxford, Oxford University Press, 2002, p. 197.

56 RAMALLO, Sebastián F. Y MURCIA, Antonio J., Op. Cit., p. 256.

57 ABASCAL, José Manuel Y RAMALLO, Sebastián F., Op. Cit., pp. 83-84.

8 ABASCAL, José Manuel Y RAMALLO, Sebastián F., Op. Cit., p. 86.

59 ABASCAL, José Manuel Y RAMALLO, Sebastián F., Op. Cit., p. 85.

60 DÍAZ ARIÑO, Borja: Epigrafía latina republicana de Hispania..., Op. Cit., p. 117; «Las murallas romanas de Cartagena...», Op. Cit., p. 229; «Epigrafia y gobernadores provinciales en Hispania...», Op. Cit., p. 171 (aunque aquí lo coloca posteriormente a su gobierno provincial sirio).

61 BARRANDON, Nathalie, De la pacification à l'intégration des Hispaniques (133-27 a.C.). Les mutations des sociétés indigènes d'Hispanie centrale et septentrionale sous domination romaine, Bordeaux, Ausonius, 2011, p. 243.

62 RIPOLLĖS, Pere Pau, Las acuñaciones provinciales romanas de Hispania, Madrid, Real Academia de la Historia, 2010, p. 122.

63 GÓMEZ-PANTOJA, Joaquín, «De Numancia a los Idus de Marzo (133-4 a.C.)», en Historia de España II. Protohistoria y Antigüedad de la Península Ibérica Vol. II. La Iberia prerromana y la Romanidad (Madrid, Sílex, 2008), pp. 357-385, en concreto p. 381.

PLÁCIDO, Domingo, Historia de España. Volumen I. Hispania Antigua, Barcelona, Istmo, 2009, pp. 315-316. 
Otra cuestión es si los dos fragmentos localizados recientemente en Carthago Nova pertenecen efectivamente a un mismo trabajo, y, por tanto, ofrecen una misma inscripción. Es posible, muy probable, pero no hay certeza absoluta. Por tanto, hay que ir con la lógica cautela, aunque nos vemos porque no tenga que ser así.

Tampoco la lectura es muy clara, puesto que, si bien para los editores se puede leer en el primer fragmento perteneciente al Palacio de Riquelme, las palabras MAGN(i) I[MP(eratoris)], por lo que puede observarse en la fotografía que adjuntan parece leerse más bien, en su lugar, MAGNV, aunque la última letra no parece demasiado clara, y podría ser MAGNI y el inicio de otra letra pero, a nuestro juicio, no es lo que indican Ramallo y Murcia. Además, ITERVM no tiene por qué ir necesariamente relacionado con Pompeyo, como se expone en la reconstrucción, sino que podría serlo con el personaje que, según los editores, efectuó realmente las obras hidráulicas; si bien hay que tener en cuenta que no existen muchos casos de iteración en las inscripciones romanas republicanas, oficiales o no ${ }^{64}$, debido a la propia carrera de Pompeyo no creemos que haya muchas dificultades en considerar que este término acompañe al general romano.

Así mismo, en la segunda reconstrucción del epígrafe que efectúan los editores, consideramos que la presencia de la palabra $\mathrm{CO}(\mathrm{n}) \mathrm{S}$ (ulis) es innecesaria y gratuita, no siendo necesario ni habiendo evidencia alguna de esta magistratura en los fragmentos conservados. Esto puede observarse en algunas de las inscripciones honorarias de Pompeyo que antes hemos mencionado.

Ya, en este sentido, no consideramos necesario que haya una tercera línea en la inscripción, de la que no existe evidencia alguna, en la que hubiese el nombre de un personaje que habría realizado la obra hidráulica en nombre de Pompeyo. Pudiera tratarse simplemente de que el lacus sólo tuviera dos líneas, una en cada lado (por lo que habría dos lados anepigráficos) o, incluso, que ésta estuviera repetida y, por tanto, cubriera todos los lados. En este sentido, hay que decir que de Pompeyo conocemos una acción evergética en la famosa ciudad de Atenas, pues le dio un donativo de cincuenta talentos (Plut. Pomp. 42, 11), dedicado a reconstruir la infraestructura portuaria de El Pireo, que había quedado destruida tras el sitio efectuado por L. Cornelio Sila (cos. I 88 a.C.) en el año 86 a.C. ${ }^{65}$ Sin ir más lejos, podemos p.e. aducir el ejemplo del epígrafe de la restauración de la Regia efectuada por Cn. Domicio Calvino (cos. II 40 a.C.) (CIL VI $1301=$ ILLRP $429=$ ILS 42), que nosotros hemos tratado en otra ocasión 66 .

64 BADIAN, Ernest, «[Sobre] Corpus Inscriptionum Latinarum. Auctarium. Inscriptiones Latinae Liberae Rei Publicae: Imágenes. Ed. A. Degrassi. Berlin: W. De Gruyter, 1966. Pp. XII+337. Numerous illus. DM. 280», JRS 58 (1968), pp. 240-249, en concreto p. 245.

65 Vid: AMELA VALVERDE, Luis, «Pompeyo Magno y Atenas», Polis, 17, (2005), pp. 7-29. 43-65.

66 Vid: AMELA VALVERDE, Luis, «Cn. Domicio Calvino y los Cerretanos», HAnt, 35, (2011), pp. 
Por tanto, a nuestro parecer, el epígrafe en cuestión no es más que una obra evergética efectuada directamente por Pompeyo, sin necesidad de la aparición de otro personaje en el texto ${ }^{67}$. No tiene por qué extrañar que un personaje romano de primer nivel, sobre todo si se trata del gobernador u otro magistrado provincial, efectuase una acción de esta categoría, sobre todo en el caso de Pompeyo, quien ya tenía planeado crear y consolidar una clientela en Hispania. Por tanto, respecto del texto, podría quedar como sigue: [CN(AEVS) POMPEIVS] MAGN(VS) I[MP(ERATOR)] ITERVM / AQVAM ADDV[C]END(AM) LAQVSQ(VE) FAC(IENDOS) $\operatorname{COER}(\mathrm{AVIT})$.

La cronología de esta inscripción sería posterior a la guerra sertoriana, como indicaría la segunda aclamación imperatorial (si se supone que la primera lectura del epígrafe ofrecida por los editores y aquí reproducida es correcta), en el que hemos de suponer que Pompeyo reorganizó Hispania (al menos la provincia Citerior), sobre todo si ha de suponerse que quien le sucedió en el cargo de gobernador fue su fiel amigo y colaborador L. Afranio (cos. 60 a.C.) ${ }^{68}$. El epígrafe sufrió damnatio memoriae, como el epígrafe honorífico dedicado a Pompeyo en Tarraco (CIL I 2964a = ELRH C59 = HAE $487=$ RIT 1 ${ }^{69}$, y ambos hechos, sin duda, deben de estar relacionados tanto con la derrota de la causa pompeyana en Hispania con la transformación de ambas ciudades, las más importantes de la provincia Citerior, en colonias romanas por parte de César o de sus herederos inmediatos ${ }^{70}$.

67 DÍAZ ARIÑO, Borja: «Epigrafia y gobernadores provinciales en Hispania...», Op. Cit., p. 169.

68 Sobre este personaje, vid: MALAVOLTA, Mariano, «Estudio sur la carrière de L. Afranius A. f. Cos.», MGR 5 (1977), 251-303.

69 RAMALLO, Sebastián F. Y RUIZ, Elena, Op. Cit., p. 103.

70 Sobre las colonias cesarianas en la Hispania Citerior, vid: AMELA VALVERDE, Luis, «Colonias y municipios cesarianos de la provincia Hispania Citerior», $A F$ (Sc. D), 10, (2000), pp. 7-33. 
